IZA DP No. 6288

Financing Entrepreneurship and the Old-Boy Network

Eren Inci

Simon C. Parker

January 2012 


\title{
Financing Entrepreneurship and the Old-Boy Network
}

\author{
Eren Inci \\ Sabanci University \\ Simon C. Parker \\ University of Western Ontario \\ and IZA \\ Discussion Paper No. 6288 \\ January 2012 \\ IZA \\ P.O. Box 7240 \\ 53072 Bonn \\ Germany \\ Phone: +49-228-3894-0 \\ Fax: +49-228-3894-180 \\ E-mail: iza@iza.org
}

\begin{abstract}
Any opinions expressed here are those of the author(s) and not those of IZA. Research published in this series may include views on policy, but the institute itself takes no institutional policy positions.

The Institute for the Study of Labor (IZA) in Bonn is a local and virtual international research center and a place of communication between science, politics and business. IZA is an independent nonprofit organization supported by Deutsche Post Foundation. The center is associated with the University of Bonn and offers a stimulating research environment through its international network, workshops and conferences, data service, project support, research visits and doctoral program. IZA engages in (i) original and internationally competitive research in all fields of labor economics, (ii) development of policy concepts, and (iii) dissemination of research results and concepts to the interested public.
\end{abstract}

IZA Discussion Papers often represent preliminary work and are circulated to encourage discussion. Citation of such a paper should account for its provisional character. A revised version may be available directly from the author. 
IZA Discussion Paper No. 6288

January 2012

\section{ABSTRACT \\ Financing Entrepreneurship and the Old-Boy Network ${ }^{*}$}

We study entrepreneurs' start-up financing from banks and local financiers. An informal network, whose membership cannot be observed by outsiders, conveys the good signals it gets about the hidden types of network entrepreneurs to local financiers, which are then reflected in different loan terms. We show that there are winners and losers as a result of the network even among its members. Because all projects have positive net value, it is efficient to finance them even in the absence of a network. Thus, the formation of the network is inefficient as entrepreneurs incur networking costs for purely redistributive gains in the form of better loan terms as network members.

JEL Classification: D82, G20, L26

Keywords: entrepreneurship, financiers, networks, start-up financing

Corresponding author:

Eren Inci

Sabanci University

Faculty of Arts and Social Sciences

Orhanli / Tuzla

34956 Istanbul

Turkey

E-mail: ereninci@sabanciuniv.edu

* The authors would like to thank Tom Astebro, Jose Guedes, Peter Thompson and other participants at the Workshop on Frontiers in Entrepreneurship Research in Lisbon. The usual disclaimer applies. 


\section{Introduction}

'Old-boy' networks are informal groupings of individuals who provide favorable referrals about co-members to third parties such as resource providers. One can think of many ways that such informal networks arise and perpetuate themselves, through personal and business interactions. Those outside the network do not enjoy these benefits and so may be disadvantaged - a well-known criticism of old-boy networks (Taylor, 2000). If informal networks reveal information that would otherwise remain hidden, there may be far-reaching implications for the nature of equilibria which arise under asymmetric information, potentially affecting efficiency and welfare (Bac and Inci, 2010). For example, even some insiders may become disadvantaged in the end.

Informal networks are distinct from formal networks (see Parker, 2008 for an analysis of the latter) in that they are neither officially recognized nor mandated as organizations in their own right and that their membership cannot be observed by outsiders. Unlike formal networks, which may be bound by legal governance structures that encourage transparency of communication, informal networks face no formal restrictions and may be able to convey a richer array of information to third parties. This is precisely the set-up we study in this paper in the particular context of entrepreneurial finance.

We develop a model comprising two hidden entrepreneurial types who both apply for external finance and whose risky project returns are ranked by first-order stochastic dominance à la de Meza and Webb (1987). Finance is provided either by banks or local financiers. An old-boy network conveys imprecise but informative signals to local financiers about the hidden types of its network members (which we call an old-boy mechanism), which are reflected in different loan contract terms. The network is initially exogenous and we ask a fundamental question: do all network entrepreneurs actually benefit from being members of the network? The answer turns out to be a qualified 'yes': high-type entrepreneurs always benefit, but low-type entrepreneurs only do so $(i)$ if the network signals are not sufficiently 
informative, (ii) if the network is small in terms of number of members, (iii) if there are relatively few high-type entrepreneurs in the economy.

The intuition for these results goes as follows. The cross-subsidization induced by the contractual structure of the credit market results in undervaluation of the start-ups of hightype entrepreneurs and overvaluation of the start-ups of low-type entrepreneurs. The old-boy mechanism alters the degrees of under- and over-valuations in the market. High-type entrepreneurs are always better off with the old-boy mechanism because signals are informative and thus they are more likely to be correctly identified by the network, in which case they are offered lower lending interest rates.

The situation is different for low-type entrepreneurs, who always want to mimic their high-type counterparts. All else equal, they prefer the old-boy mechanism when the network signals are not sufficiently informative so that they can have a higher chance of not being correctly identified. All else equal, they also want to be in a smaller network, because their payoff is the same regardless of the size of the network if they are not correctly identified, but if they are correctly identified and left out of the network, the fraction of high-type entrepreneurs will be relatively larger outside the network when the network is small and they have positive externalities on the loan prices offered to low-type entrepreneurs. Thus, while the upside benefit of being in the network remains the same, the downside is relatively less important when the network is small. Once the network becomes sufficiently small, then low-type entrepreneurs prefer the old-boy mechanism over the no-network regime.

Finally, all else equal, a low-type entrepreneur prefers the old-boy mechanism when the fraction of high-type entrepreneurs in the society is sufficiently low. Having a lower fraction of high-type entrepreneurs has both upsides and downsides to low-type entrepreneurs. The upside is that they may not be correctly identified in which case their projects are going to be even more overvalued in such a society. The downside is that they might be correctly identified in which case the lending interest rate is going to be higher for low types. However, 
because the fraction of high-type entrepreneurs is already low enough, this outcome is not so much different than the case in which there is no old-boy mechanism operating in the market. Thus, the upside is relatively more important than the downside in expected payoff when the fraction of high-type entrepreneurs in the society is sufficiently low.

If low-type entrepreneurs do not benefit from the old-boy mechanism, do they lose more than their high-type counterparts gain - and if so, can they prevent the old-boy mechanism from operating? We find the answers to both questions are negative. The crucial point here is that when the network is sufficiently small, both high- and low-type entrepreneurs prefer the old-boy mechanism and side payments promised by them can be sufficient incentives for the network owner to organize it. When the network is large, there is conflict of interest between the different types. Yet, we show that the maximum amount of side payments that high-type entrepreneurs are willing and able to pay to the network owner is higher than that of their low-type counterparts. This implies that there are incentives for the network owner to form the old-boy mechanism in this case, too. ${ }^{1}$ Even in such a situation, low-type entrepreneurs do not want to leave the network but rather cripple its information mechanism. They know that the network will form anyway as a result of high-type entrepreneurs' side payments and thus they want to be network members in any case to keep their chance of being not correctly identified. Finally, we show that our results are robust to the existence of network operating costs and a device (co-financing by networks) to establish the credibility of the signals.

All the results reported so far are established in a model in which the network is exogenous, and this exogenous network model highlights the important effects clearly. However,

\footnotetext{
${ }^{1}$ To be precise, we demonstrate the existence of market incentives to engage in information extraction. As long as some kind of excess value is created as a result of the old-boy mechanism, it will be exploited in some way or another. The side payments are not necessarily bribes or anything that sort. They may take various forms. For example, network entrepreneurs can sell a share of their start-ups to the network owner which may well be realized under market prices. There are many other examples of transactions occurring under the market prices in the interlinkage literature (see Ray, 1998). For example, landlords lend money to their tenants, and tenants repay it by working for the landlords at lower wage rates than their marginal productivity.
} 
in this model, the network owner has an exogenous referral policy of revealing information about only the entrepreneurs with good signals. To show the generality of our result, we then endogenize network formation by allowing entrepreneurs to differ in their networking costs. We show that not only is our assumed network structure sound, but also the assumed referral policy is in fact optimal for the network owner when its objective is to maximize the total welfare of its members.

The endogenous network model also clearly shows that networks can form even though they are inefficient. The intuition goes as follows. Because all projects have positive net value, it is efficient to finance all entrepreneurs even when there is no network. The network forms only because its members enjoy private gains via financing through the old-boy mechanism, which is a purely redistributive gain. Thus, the fact that entrepreneurs incur networking costs is inefficient from the point of view of the society because all who should be financed would have been financed even in the absence of a network. Moreover, the network in our setting is not nepotistic in the sense of conveying untruthful signals about network members; so, our results cannot be attributable to nepotism. Finally, making the costs vary among entrepreneurs shows that even some of the high-type network entrepreneurs can be losers due to the old-boy mechanism.

While informal networks are well-known in sociology, they have been less widely studied in economics (see Scott (1991) for a sociological inquiry into informal networks, and Ioannides and Loury (2004) for a survey on the role of social networks in labor markets). This paper adds to a small but growing economics literature on entrepreneurial networks. Parker (2008) focuses on the private and social benefits generated by business networks, and analyzes aspects of optimal network design. He shows that in general networks are generally too small to maximize social welfare. However, his paper deals with formal rather than informal networks, and does not discuss the role of start-up finance.

Bac and Inci (2010) explore the welfare implications of informal networks in a setting 
where entrepreneurs seek external finance and types are endogenous. Although they do not analyze different incentives for entrepreneurs to join networks — the subject of the present paper - it is noteworthy that they too establish potentially negative impacts from network organizations which are commonly assumed to be unambiguously 'positive'. In Bac and Inci (2010), an entrepreneur chooses between remaining a low type and becoming a high type by providing effort. The network outcome can be inefficient because too few entrepreneurs may choose to become high types as compared with the no network outcome. Because the overall type distribution is fixed throughout the current paper, the inefficiency of the network outcome occurs for a different reason than Bac and Inci (2010). Saloner (1985) looks at a similar problem. In his setting, intermediaries decide whom to recommend from a group of individuals about whom they have private information. Then, the employer makes decisions based on his expectation about the quality of both the recommended and unrecommended applicants, which resembles the functioning of the credit market in our setting.

We do not claim that social networks provide no benefits to their members. Indeed, there is evidence that they do, with Nanda and Khanna (2010) finding that Indian entrepreneurs who lived abroad obtain easier access to finance when they move back to India, by virtue of being able to tap cross-border networks. Instead, our point is that there are 'losers' as well as 'winners' from networks, owing to the separation of heterogeneous types which potentially undoes a cross-subsidization between those types; and it is by no means obvious a priori that the winners win more than the losers lose.

We do not claim that informal networks are the only information channels between entrepreneurs and their financiers. For instance, there is a well-established literature discussing how informed venture capital can overcome information asymmetries by monitoring, allocating control rights and staging capital to entrepreneurs (see, for example, Bergemann and Hege, 1998; Cornelli and Yosha, 2003; Kaplan and Stromberg, 2001). In fact, some researchers argue that these mechanisms are unsuitable for resolving contracting problems in early stage start-ups, where social ties and social norms of fairness and obligation may be 
more important (Shane and Cable, 2002). While the informal networks we study do leverage social ties, they do so without resorting to direct investment by either business angels (Amatucci and Sohl, 2007) or what Nofsinger and Wang (2011) refer to as 'informal investors'. Thus, the types of networks we study are distinct from, and complementary to, alternative sources of entrepreneurial financing studies in prior literature. An important contribution of our paper is to show that even though they do not act as investors themselves, informal networks still impact the efficiency of credit markets.

Our results carry some interesting implications for contracting under asymmetric information. It is commonly believed in the literature that there are no motives for third parties to engage in information extraction in simple market regimes with information asymmetries. The intuition for this claim goes as follows. When there is pooling equilibrium in the credit markets - which is the case in this paper - the market overvalues the start-ups of low-type entrepreneurs and undervalues the start-ups of high-type entrepreneurs. Given perfect (or Bertrand) competition among lenders and regular pooling contracts, the level of over- and undervaluation exactly matches each other in the aggregate. Thus, in equilibrium, there cannot be market incentives for a 'third party' to engage in information extraction in this simple market regime (see Campbell and Kracaw (1980) for this line of reasoning). Our results show that this claim is overruled when there is a network organization because then the network owner as a third party has market incentives to decrease the information gap between entrepreneurs and their financiers.

Numerous prior studies have explored how various contracting devices can break pooling equilibria and induce separating equilibria which mitigate adverse selection or moral hazard (e.g., collateral (Bester, 1985), restrictions on limited liability (Chamley, 1983), forfeiture and anti-dilution provisions (Diamond, 1993) and education (Orzach and Tauman, 2005)). A common feature of these studies is their claim that contracting devices can enhance efficiency. It is, therefore, interesting to ask how the device of informal networks compares in this regard. Although there is no ex ante inefficiency in the model we analyze, it turns out that informal 
networks can introduce inefficiency in the form of wasteful networking costs.

The remainder of the paper has the following structure. Section 2 outlines the model and analyzes financing arrangements in the absence of an informal network. Section 3 analyzes financing arrangements in the presence of an exogenous informal network. Section 4 determines the winners and losers due to the old-boy mechanism. Section 5 endogenizes the informal network for the case where entrepreneurs choose whether to incur networking costs to join the network and the network owner chooses what types of signal to convey to local financiers. Section 6 concludes. An appendix contains proofs and extensions.

\section{The model}

We consider a unit mass of risk-neutral entrepreneurs, each of whom is endowed with a start-up project that requires one unit of start-up capital. For simplicity, we assume that entrepreneurs have no wealth. Therefore, they need to borrow the start-up capital from a lender. There is also a network formed by an established hub firm. $\eta \in(0,1)$ of the entrepreneurs are in the network (network entrepreneurs) and $1-\eta$ of them are outside the network (stand-alone entrepreneurs). To start with, we take $\eta$ to be fixed and exogenous, but we endogenize it in Section 5 .

The network is informal and thus affiliation is not directly observable by lenders. ${ }^{2}$ Members of such networks incur networking costs, which may be interpreted as resources that must be expended in order to build the social relationships, which provide access to informal networks. For example, entrepreneurs might have to spend time and money attending exclusive social functions and sponsoring events in order to become and remain known among

\footnotetext{
${ }^{2}$ Technically, we assume a star network structure among the hub firm and entrepreneurs. As evidenced by Lamoreaux et al. (2007), agglomerations can often be tracked down to one or two hub firms that act as incubators for new firms. For simplicity, we assume that there is one such firm. The analysis can easily be generalized to a case in which there are more than one hub firm. However, there is no harm in perceiving the hub firm as a representative of all hub firms for our purpose in this paper, just as we do with a representative consumer in consumption theory.
} 
influential decision makers. This section, and the one after, abstracts from such networking costs, but they are introduced in Section 4, where we treat them as a fixed monetary payment, $c$, incurred by all network entrepreneurs. Section 5 relaxes this assumption by allowing networking costs to vary among entrepreneurs.

There are two different kinds of start-up projects. A good (high success probability) project succeeds with probability $p_{H} \in(0,1)$ whereas a not-so-good (low success probability) project succeeds with probability $p_{L}<p_{H}$. An entrepreneur who is endowed with a good (not-so-good) project is called a high-type (low-type) entrepreneur. Entrepreneurs privately know their types, but the distribution of types is common knowledge within and outside the network. High-type entrepreneurs make up a $\theta \in(0,1)$ fraction of each population. ${ }^{3}$ Given this, there are $\theta \eta$ high-type network entrepreneurs and $(1-\theta) \eta$ low-type network entrepreneurs. The corresponding numbers for stand-alone entrepreneurs are $\theta(1-\eta)$ and $(1-\theta)(1-\eta)$, respectively.

A project yields $Y$ units of capital in the case of success, and zero in the case of failure. With our specifications, the projects are ranked according to their expected payoffs, as in standard de Meza and Webb (1987) class of credit market models. The cost of loanable funds is equal to the risk-free (gross) interest rate $R$ in the economy. All projects have positive net value, which is stated in the following assumption.

\section{Assumption 1 (Net Values of Projects) $p_{H} Y>p_{L} Y>R$.}

That is why we name projects 'good' and 'not-so-good' rather than 'good' and 'bad'. Therefore, it is not only the case that all entrepreneurs would prefer to undertake their projects had they been able to fully self-finance them, but also that lenders would prefer financing all projects. If we assume, instead, that not-so-good projects have negative net

\footnotetext{
${ }^{3}$ Our results remain qualitatively the same even when the network comprises a higher fraction of hightype entrepreneurs than outside it. See Appendix B.1 for such an extension.
} 
values, there will be cases in which the credit market shuts down for some group of entrepreneurs as in Akerlof-type models, and this leads to extreme (but trivial) versions of our results. The focus of this paper is not on the inefficiencies that arise because of the lemons problem in the credit market, but rather on the pricing problem of different projects and the resulting incentive scheme that may induce the construction of a network. ${ }^{4}$

The lenders are risk neutral and they are in Bertrand competition with each other. They can be either banks or local financiers. These two types of lenders are identical in all respects except the information they are privy to. They form their beliefs simultaneously and choose the contracts they will offer taking as given the cost of loanable funds. For the moment, we assume that both banks and local financiers have the same information set. Later, we will allow local financiers to make use of local information available from the hub firm.

Loan contracts are contingent on the announced type and the project outcome (either success or failure). They specify the repayments to the lenders for both outcomes. Let the repayment be $D_{i}^{S}(R)$ in the success state and $D_{i}^{F}(R)$ in the failure state, where $S$ stands for success and $F$ for failure, and $i=\{H, L\}$ is the type of the entrepreneur. We assume that there is limited liability, and therefore, contracts cannot leave entrepreneurs with negative end-of-period payoffs.

An entrepreneur is successful with probability $p_{i}$ in which case she produces $Y$ and gives $D_{i}^{S}$ of it to the bank. In the case of failure, the entrepreneur produces something less than $Y$ (which is normalized to zero) and gives $D_{i}^{F}$ of it to the bank. However, limited liability prevents $D_{i}^{F}$ from being higher than what the entrepreneur has. Since the low output is normalized to zero, it follows immediately that $D_{i}^{F}=0$ as well. Consequently, the expected payoff of an entrepreneur at the beginning of the period, $\Pi_{i}$, is given by

$$
\Pi_{i}=p_{i}\left(Y-D_{i}^{S}(R)\right) \geq 0 \quad \forall i \in\{H, L\} .
$$

\footnotetext{
${ }^{4}$ Inci (2006) focuses on such inefficiencies by assuming that not-so-good projects have negative net value.
} 
The sequence of events is as follows. First, the hub firm receives good signals about some fraction of the network entrepreneurs. It gets no signal about the rest of them. Those who get good signals are mentioned to the local financiers who will eventually finance them. ${ }^{5}$ However, as will become clear later, those who are not able to produce signals will apply for loans as if they were stand-alone entrepreneurs. Next, entrepreneurs sign financial contracts with lenders and make their investments. Finally, successful entrepreneurs pay off their loans once their payoffs are realized.

We use the standard Bertrand-Nash equilibrium concept. Each lender offers entrepreneurs a contract that maximizes its profits. Then, among all alternatives, entrepreneurs choose the best contract for them. Under these conditions, it is impossible to design contracts such that different types of entrepreneurs self-select themselves into different contracts unless we drop the limited liability assumption. ${ }^{6}$ In other words, it is impossible to identify which entrepreneurs are high types since it is always beneficial for a low-type entrepreneur to misrepresent herself as having a good project. In the absence of a network, the outcome is therefore a pooling equilibrium, where ${ }^{7}$

$$
D_{H}^{S}(R)=D_{L}^{S}(R)=D^{S}=\frac{R}{\bar{p}} \quad, \quad D_{H}^{F}(R)=D_{L}^{F}(R)=D^{F}=0
$$

and

$$
\bar{p}=\theta p_{H}+(1-\theta) p_{L}
$$

Note that $\partial \bar{p} / \partial \theta>0$. This equilibrium pooling contract takes the simple debt form with a repayment of $R / \bar{p}$ in the success state and zero repayment in the failure state. The effective

\footnotetext{
${ }^{5}$ Section 5 endogenizes the hub firm's signal referral policy.

${ }^{6}$ Dropping the limited liability assumption would result in "pound of flesh" contracts that require asking for something that an entrepreneur does not have.

${ }^{7}$ Semi-pooling contracts would also be possible if not-so-good projects had negative net value, but this is ruled out by Assumption 1. In a semi-pooling loan market equilibrium, all high-type entrepreneurs but only a fraction of low-type entrepreneurs participate in the loan market until the lending interest rate becomes so high that low-type entrepreneurs make zero expected profits whether they take a loan or not. See Bac and Inci (2010) for an analysis of such semi-pooling contracts.
} 
interest rate implied by this contract is $R / \bar{p}$.

\section{Local financiers and the old-boy mechanism}

We now turn to the case where the hub firm has a role in start-up financing, retaining for now the assumption that a network is already in place. We also continue to abstract for

now from networking costs borne by entrepreneurs. Remember that the hub firm gets a good signal about the type of some network entrepreneurs but no signal about the rest. We assume that this information is costless and comes naturally due to interaction between the parties. The hub firm has close links with local financiers, too. These links can be the result of ongoing or past financial relationships. The crucial point is that the hub firm can share its information with local financiers, as evidenced in Lamoreaux et al. (2007).

Let $\sigma$ be hub firm's information. $\sigma=1$ if it gets a good signal about a network entrepreneur and $\sigma=0$ if it gets no signal about the entrepreneur. Receiving a signal about a particular network entrepreneur (or not receiving it) allows the hub firm to form its beliefs about each network entrepreneur. The probability of a good signal for a high-type entrepreneur is $x \in(0,1)$ and that for a low-type entrepreneur is $y \in(0,1)$.

Denote the set of network entrepreneurs by $N$. Conditional on a good signal, the Bayesian probability that a loan applicant is a high-type entrepreneur is

$$
\operatorname{Pr}\{i=H \mid \sigma=1 \wedge i \in N\}=\frac{\theta x}{\theta x+(1-\theta) y},
$$

and conditional on not getting a signal, the Bayesian probability that a loan applicant is a high-type entrepreneur is

$$
\operatorname{Pr}\{i=H \mid \sigma=0 \wedge i \in N\}=\frac{\theta(1-x)}{\theta(1-x)+(1-\theta)(1-y)}
$$


Similar expressions for the Bayesian probabilities that a loan applicant is a low-type entrepreneur are given by

$$
\begin{aligned}
& \operatorname{Pr}\{i=L \mid \sigma=1 \wedge i \in N\}=\frac{(1-\theta) y}{\theta x+(1-\theta) y} \\
& \operatorname{Pr}\{i=L \mid \sigma=0 \wedge i \in N\}=\frac{(1-\theta)(1-y)}{\theta(1-x)+(1-\theta)(1-y)} .
\end{aligned}
$$

The signal structure is imperfect because the hub firm does not receive a signal about a high-type entrepreneur with probability $1-x$, and it receives a good signal about a lowtype entrepreneur with probability $y$. However, we assume that the signals are useful on average. Technically, this is achieved if the monotone likelihood ratio property holds for the distribution of types. For this simple model, this requires the ratio of the Bayesian probability of a good signal to no signal to be increasing with the type of the entrepreneur. That is, the fact that the ratio $(4) /(5)$ is greater than the ratio $(6) /(7)$ should hold, which boils down to the following assumption.

\section{Assumption 2 (Informativeness of Signals) Signals are informative: $x>y$.}

The entrepreneurs getting good signals are mentioned to at least two local financiers who trust the beliefs of the hub firm. ${ }^{8}$ This information is private between the hub firm and the local financiers and cannot be credibly communicated to anyone else. As a result, local financiers have access to the local information that a bank cannot gather. However, local financiers do know that the hub firm has contacts with other local financiers, too. We also assume that the hub firm communicates the good signals to the local financiers honestly. ${ }^{9}$

\footnotetext{
${ }^{8}$ Observing an entrepreneur without a signal is, of course, informative in its own right and could alternatively be labeled as a "bad signal". The crucial assumption here is that the hub firm shares only the good signals with the local financiers. This rules out the possibility of financiers distinguishing between standalone entrepreneurs and network entrepreneurs with bad signals, which is quite realistic given that network membership is not observable by outsiders. Section 5 shows that this referral policy is in fact optimal for the hub firm if its objective is to maximize the total welfare of network members.

${ }^{9}$ Appendix B.2 discusses how to guarantee the reliability of signals.
} 
In the case where there is no old-boy mechanism, the average success probability of the loan applicant pool is given by $\bar{p}$, and as is shown in (2), the equilibrium lending interest rate is $R / \bar{p}$ for any loan granted. However, the extra information that the local financiers receive enables them to price discriminate between network entrepreneurs with good signals and the rest.

The average success probability of network entrepreneurs with good signals, $\hat{p}$, is

$$
\hat{p}=\frac{\theta x p_{H}+(1-\theta) y p_{L}}{\theta x+(1-\theta) y}
$$

Note that $\partial \hat{p} / \partial \theta>0$. A similar analysis that of the previous section, but with new (Bayesian) incentive constraints and (Bayesian) zero-profit conditions shows that local financiers offer a lending interest rate of $R / \hat{p}$ to any network entrepreneur with a good signal. A simple comparison of (3) and (8) shows that $\hat{p}>\bar{p}$ as long as $x>y$, which holds by Assumption 2. Therefore, the existence of a network allows local financiers to provide cheaper loans to network entrepreneurs with good signals.

The average success probability of the stand-alone loan applicants is $\bar{p}$. However, network membership is not observable by banks, and local financiers are made aware of only the entrepreneurs with good signals. Thus, network entrepreneurs who did not get a good signal will apply for loans as if they were stand-alone entrepreneurs. This changes the average success probability of the stand-alone loan applicants. Knowing this, banks and local financiers price their loans accordingly. The new average success probability outside the network is now given by

$$
\tilde{p}=\frac{(1-x \eta) \theta p_{H}+(1-y \eta)(1-\theta) p_{L}}{(1-x \eta) \theta+(1-y \eta)(1-\theta)}
$$

It is easy to show that $\tilde{p}<\bar{p}, \partial \tilde{p} / \partial \eta<0$, and $\partial \tilde{p} / \partial \theta>0$. The reason for $\tilde{p}<\bar{p}$ is the following. The average success probability of the whole population is $\bar{p}$. A portion of this 
population, which has an average success probability of $\hat{p}>\bar{p}$, is in the network. Therefore, the average success probability of the remaining population has to be less than $\bar{p}$.

\section{Winners and losers in the old-boy network}

Continuing for now to take the existence of an old-boy network as exogenous, we can now ask whether all entrepreneurs benefit equally from such a network, or whether some entrepreneurs benefit while others are disadvantaged. We show that the answer depends on several network characteristics, including its size. If the network is small, all network entrepreneurs are winners. If the network is large, high-type network entrepreneurs are winners while their low-type counterparts are losers; but the former gain more than the latter lose. Thus, whether the network is large or small, the network can be maintained. This means that network members are even willing to incur a networking cost to separate themselves from non-members to obtain a purely redistributive gain. This is, however, inefficient from the viewpoint of society, because, whether there is a network or not, all projects are financed in this model anyway, but a wasteful networking cost is incurred by network members in the former.

Continuing to abstract from networking costs momentarily, note that in the presence of asymmetric information, credit markets undervalue the start-ups of high-type entrepreneurs while they overvalue the start-ups of low-type entrepreneurs. From an ex ante point of view, in the absence of an old-boy mechanism, the value of a start-up is

$$
\overline{\mathcal{V}}_{i}=p_{i}\left(Y-\frac{R I}{\bar{p}}\right) \quad \forall i=\{H, L\}
$$

for a type $i$ entrepreneur.

The old-boy mechanism changes the levels of under- and overvaluation of start-ups. Now, a high-type entrepreneur gets a good signal with probability $x$, in which case she stays in 
the network, is offered a lending interest rate of $R / \hat{p}$, and produces $Y$ units if successful. However, in the failure state, which happens with probability $1-x$, she gets no signal and as a result is left out of the network. In such a case, she is offered a lending interest rate of $R / \tilde{p}$, which is higher than $R / \hat{p}$. Consequently, when there is an old-boy mechanism, the value of the start-up of a high-type network entrepreneur, $\mathcal{V}_{H}$, is

$$
\mathcal{V}_{H}=x p_{H}\left(Y-\frac{R}{\hat{p}}\right)+(1-x) p_{H}\left(Y-\frac{R}{\tilde{p}}\right)
$$

Similarly, the value of the start-up of a low-type network entrepreneur, $\mathcal{V}_{L}$, is

$$
\mathcal{V}_{L}=y p_{L}\left(Y-\frac{R}{\hat{p}}\right)+(1-y) p_{L}\left(Y-\frac{R}{\tilde{p}}\right)
$$

Given that the distribution of types within and outside the network are the same, an entrepreneur's decision between network membership and standing alone is found by comparing $\overline{\mathcal{V}}_{H}$ with $\mathcal{V}_{H}$ and $\overline{\mathcal{V}}_{L}$ with $\mathcal{V}_{L}$. The following proposition proves that a high-type network entrepreneur always prefers the old-boy mechanism, but the preference of a lowtype network entrepreneur depends on the informativeness of the signals, the network size, and the fraction of high-type network entrepreneurs.

Proposition 1 (Entrepreneur's Decision) a) A high-type network entrepreneur always prefers the old-boy mechanism. b) A low-type network entrepreneur prefers the old-boy mechanism when

1. the signals are not sufficiently informative, given the network size and the fraction of high-type entrepreneurs:

$$
\frac{x}{y}<\frac{\theta p_{H}+(1-\theta)(1-\eta) p_{L}}{\eta \theta p_{H}}
$$

2. the network is sufficiently small, given the signal structure and the fraction of high-type 
entrepreneurs:

$$
\eta<\frac{y\left(\theta p_{H}+(1-\theta) p_{L}\right)}{\theta x p_{H}+(1-\theta) y p_{L}},
$$

3. the fraction of high-type entrepreneurs is sufficiently low, given the network size and the signal structure:

$$
\theta<\frac{p_{L} y(1-\eta)}{(x \eta-y) p_{H}+y(1-\eta) p_{L}} .
$$

(a) If the network is sufficiently small (i.e., $\eta<y / x)$ and $(x \eta-y) p_{H}+p_{L} y(1-\eta)>0$, then all $\theta \in(0,1)$ satisfy (15).

(b) If $(x \eta-y) p_{H}+p_{L} y(1-\eta)<0$, then there is no $\theta$ satisfying (15).

Here, (13)-(15) show the same condition in different ways. This important proposition, whose proof is given in Appendix A.1, requires a detailed treatment. The reason for the results is that the pricing of start-up projects is not first best. The cross-subsidization induced by the contractual structure of the credit market results in a redistribution of wealth from the owners of undervalued start-up projects to the owners of overvalued start-up projects. The old-boy mechanism can improve the situation by mitigating the adverse selection problem for some network entrepreneurs. Ex ante, high-type network entrepreneurs have the chance of getting a good signal with probability $x$ while they may also not get a signal, in which case their projects are going to be even further undervalued. However, it turns out that, as long as signals are informative, the former dominates the latter in expected payoff.

The situation is different for low-type network entrepreneurs. They always want to misrepresent themselves as having good projects. Given a network of a fixed size and a fixed fraction of high-type entrepreneurs, low-type network entrepreneurs still have a chance to be labeled with a good signal if the signals are not very informative. This increases the level of overvaluation to even higher levels. However, if the signals are sufficiently informative, they are more likely to get no signals by the old-boy mechanism, in which case they get loans with an interest rate of $R / \tilde{p}$. 
All else equal, low-type entrepreneurs prefer smaller networks because, even though their payoff realization when they get a good signal and stay in the network is independent of the network size (which is related to $\hat{p}$, as shown in the first term of the LHS of $(\mathrm{A}-3)$ ), their realized payoff in case of no signal (which is related to $\tilde{p}$, as shown in the second term of LHS of (A-3)) is decreasing in the network size. Thus, their expected payoff, which is the weighted average of the previous two realized payoffs, is also decreasing in the network size. Consequently, this expected payoff becomes higher than their payoff without the network (which is independent of network size) as the network becomes sufficiently smaller. Thus, low-type network entrepreneurs are better off in a sufficiently smaller network for any given signal structure and fraction of high-type entrepreneurs.

Proposition 1 also shows that, all else equal, low-type network entrepreneurs benefit from being in a network when there is a smaller fraction of high-type entrepreneurs in the population. When there are many high-type entrepreneurs, a low-type entrepreneur will not benefit greatly from being in the network, as in that case $\hat{p}$ will be little greater than $\bar{p}$. But if she does not get a signal, she will have to stand alone outside the network with a significantly smaller number of high-type entrepreneurs because many of them will be correctly detected by the network and so will stay in the network. In this case, $\tilde{p}$ will be substantially lower than $\bar{p}$ - so the downside is relatively more important in terms of expected payoff.

In summary, low-type network entrepreneurs are likely to be worse off with the old-boy mechanism in large networks with an effective signaling structure in societies containing a larger fraction of high-type entrepreneurs. They are likely to be better off with the old-boy mechanism in smaller networks with a cumbersome signaling structure in societies containing a smaller fraction of high-type entrepreneurs. ${ }^{10}$

It is noteworthy that whether an entrepreneur prefers the old-boy mechanism over no

\footnotetext{
${ }^{10}$ Our results do not hinge on the assumption that the fraction of high-type network entrepreneurs is the same both in and outside the network. Appendix B.1 shows that the same results hold even when the fraction of high-type network entrepreneurs is higher than the fraction of high-type stand-alone entrepreneurs.
} 
network is not equivalent to whether an entrepreneur prefers staying in the network or not. In particular, low-type network entrepreneurs do not want to leave the network even when they do not want the old-boy mechanism to operate, simply because the expected success probability of a low-type network entrepreneur in the presence of the old-boy mechanism, $y \hat{p}+(1-y) \tilde{p}$, is always larger than the expected success probability outside the network, $\tilde{p}$, even though the former expression can be larger or smaller than the success probability without the network, $\bar{p}$. Thus, if they leave the network, the success probability outside the network will be much lower since high-type network entrepreneurs will stay in the network. This would result in higher loan prices in equilibrium for low-type network entrepreneurs if they leave the network, which suggests that they want to maintain the network's unity.

Proposition 1 derives preferences at the individual level. The straightforward corollary to this proposition states the preferences of network entrepreneurs as a group for the case in which the network is sufficiently small. A further proposition will do the same when the network is large.

Corollary 1 (Entrepreneurs' Decision as a Group in a Small Network) When the network is small (i.e., $\left.\eta<\left[y\left(\theta p_{H}+(1-\theta) p_{L}\right)\right] /\left[\theta x p_{H}+(1-\theta) y p_{L}\right]\right)$, both high-and low-type entrepreneurs prefer the old-boy mechanism as a group.

This result says that when there is no conflict of interest between high- and low-type entrepreneurs (i.e., when $\mathcal{V}_{H}-\overline{\mathcal{V}}_{H}>0$ and $\mathcal{V}_{L}-\overline{\mathcal{V}}_{L}>0$ ), the old-boy mechanism maintains itself easily. The more interesting case, which we will now focus on, is the case in which the network is sufficiently large (i.e., $\left.\eta>\left[y\left(\theta p_{H}+(1-\theta) p_{L}\right)\right] /\left[\theta x p_{H}+(1-\theta) y p_{L}\right]\right)$. In this case, there is a conflict of interest between the two groups of entrepreneurs (i.e., $\mathcal{V}_{H}-\overline{\mathcal{V}}_{H}>0$ but $\left.\mathcal{V}_{L}-\overline{\mathcal{V}}_{L}<0\right)$. A high-type network entrepreneur prefers the old-boy mechanism and thus is willing to make a side payment to the hub firm to maintain the old-boy mechanism. This side payment can at most be $\mathcal{V}_{H}-\overline{\mathcal{V}}_{H}$. On the other hand, a low-type network entrepreneur 
does not want the old-boy mechanism and thus is willing to make a side payment to the hub firm to induce it to dissolve it. This side payment can at most be $\overline{\mathcal{V}}_{L}-\mathcal{V}_{L} \cdot{ }^{11}$

Whether the hub firm maintains the old-boy mechanism depends on the total side payments from both groups of entrepreneurs. Campbell and Kracaw (1980) claim that there would be no incentives to engage in information extraction in a simple market with information asymmetries, a result they call the "nonexistence of rational expectations equilibrium." The basic intuition for the nonexistence result is that, because banks make zero profits, the overvaluation of the start-ups of low-type entrepreneurs must exactly match with the undervaluation of the start-ups of high-type entrepreneurs in equilibrium. In our setting, the equalities of overvaluation to undervaluation correspond to the following equalities:

$$
\begin{aligned}
\theta(1-x \eta)\left(p_{H}-\tilde{p}\right) & =(1-\theta)(1-y \eta)\left(\tilde{p}-p_{L}\right) \\
x \theta\left(p_{H}-\hat{p}\right) & =y(1-\theta)\left(\hat{p}-p_{L}\right) .
\end{aligned}
$$

Eq. (16) establishes the cross-subsidization among high- and low-type entrepreneurs who are either stand-alone or dismissed from the network. $\theta(1-\eta)$ of the stand-alone entrepreneurs and $(1-x) \eta \theta$ of the entrepreneurs who are dismissed from the network are high types, which makes $\theta(1-x \eta)$ in total, as shown on the left-hand side of (16). While $(1-\theta)(1-\eta)$ of the stand-alone entrepreneurs and $(1-y) \eta(1-\theta)$ of the entrepreneurs who are dismissed from the network are low type, which makes $(1-\theta)(1-y \eta)$ in total, as shown on the right-hand side of (16). Eq. (17) focuses on the cross-subsidization among the network entrepreneurs who finance their start-ups with privileged loans ( $x \theta$ of them are high-type entrepreneurs and $y(1-\theta)$ of them are low-type entrepreneurs). These equations establish Campbell and Kracaw's intuition. However, the crucial points here are that there is no

\footnotetext{
${ }^{11} \mathrm{~A}$ word of caution is required here. The side payment expressions here are in fact average side payments. Given that there is limited liability, an entrepreneur's side payment can be different depending on whether the entrepreneur is in a success or a failure state. However, given that there is a continuum of types, the Law of Large Numbers applies and we can calculate the total side payments of a group of entrepreneurs from these average expressions.
} 
reason to believe that the total amounts of overvaluation and undervaluation among network entrepreneurs are equal to each other because stand-alone entrepreneurs are naturally not included in this group, and if it is not so, that there will be market incentives to form the old-boy mechanism. The following proposition proves that these are in fact the cases.

Proposition 2 (Entrepreneurs' Decision as a Group in a Large Network) When the network is large (i.e.; $\left.\eta>\left[y\left(\theta p_{H}+(1-\theta) p_{L}\right)\right] /\left[\theta x p_{H}+(1-\theta) y p_{L}\right]\right)$, the total increase in the market value of the start-ups of high-type network entrepreneurs because of the old-boy mechanism is higher than the total decrease in the market value of the start-ups of low-type network entrepreneurs.

The proof is in Appendix A.2. We can now combine all results so far to establish the market incentives for maintaining an exogenous old-boy mechanism. When the network is small, all network entrepreneurs want the old-boy mechanism to operate and would be willing and able to make side payments to the hub firm to maintain it (Proposition 1 and Corollary 1). When the network is sufficiently large, high-type network entrepreneurs are willing and able to offer side payments to the hub firm to induce it to maintain the old-boy mechanism, and low-type network entrepreneurs are willing and able to offer side payments to the hub firm to dissolve it (Proposition 1). However, what the former group is willing and able to pay is always larger than what the latter group is willing and able to pay (Proposition 2). Therefore, regardless of the size of the network, there are incentives to maintain an exogenous old-boy mechanism in this simple market structure with information asymmetries. This result is summarized in the following corollary.

Corollary 2 (Incentives to Maintain an Old-boy Mechanism) There are market incentives for the hub firm to maintain an old-boy mechanism.

This result points to the existence of a surplus (in this case the possibility of side payments) that can be directed towards maintaining the network. The presence of a surplus 
means that our results are robust to costs of network membership, provided that the costs are not prohibitive. Let $c>0$ be the cost per network entrepreneur of network membership. This could be, for example, costs of signal extraction borne by the hub firm; alternatively, it could be costs of networking needed to remain in a network, that are directly borne by the members. In either case, provided $c \leq \mathcal{V}_{H}-\overline{\mathcal{V}}_{H}$, network entrepreneurs with undervalued projects are willing to use their surplus to defray the cost. Since it has been established that the total amount of side payments by the network entrepreneurs with undervalued projects is greater than that by the network entrepreneurs with overvalued projects, there can be incentives to form and maintain the old-boy mechanism if $c \leq \theta\left(\mathcal{V}_{H}-\overline{\mathcal{V}}_{H}\right)+(1-\theta)\left(\overline{\mathcal{V}}_{L}-\mathcal{V}_{L}\right)$. Thus, our results extend to the case where membership of the network is costly. The importance of this result is that it shows the possibility that asymmetric information may result in an inefficient network organization.

Proposition 3 (Inefficient Networking Costs) An old-boy network may entail entrepreneurs inefficiently incurring networking costs for purely redistributive private gains as network members.

\section{$5 \quad$ Endogenizing the old-boy network}

The analysis so far has assumed that a hub firm exists and that it conveys signals to local financiers as outlined in Section 3. This section endogenizes both network membership and the hub firm's signal referral policy by making two assumptions. First, the hub firm is assumed to maximize a utilitarian social welfare function defined over the set of network members. This objective function is consistent with the informal nature of the network based on social contacts, which values all members equally. Below, we will see that the key

results continue to hold even if the hub firm favors high types over low types. Second, we assume that entrepreneurs differ in their networking costs. This assumption seems plausible 
because some entrepreneurs might have friends or family who know the hub firm personally, and presumably, their networking costs are lower than those of less fortunate entrepreneurs who have to spend time and money to become acquainted with the hub firm at exclusive social functions.

If networking costs are incurred, we assume for simplicity that these costs do not need to be paid again. We also assume that these costs are publicly non-verifiable and independent of investment project type. Unlike the previous section, which simply compared outcomes when an informal network exists and when it does not, the emphasis now is on entrepreneurs choosing whether or not to pay a cost to join a network given that other entrepreneurs also face this choice. So, the inefficiency of the network we mention in Proposition 3 will be more clearly identified here as the decision to enter the network now becomes a choice variable.

Entrepreneurs compare the payoff from network membership, $\mathcal{V}_{i}$, with the payoff from non-membership, $\tilde{\mathcal{V}}_{i}$. Here, $\mathcal{V}_{i}$ is given by (11) and (12), while

$$
\tilde{\mathcal{V}}_{i}=p_{i}\left(Y-\frac{R}{\tilde{p}}\right) \quad \forall i=\{H, L\}
$$

The $\tilde{p}$ in this expression differs slightly from that derived in the exogenous case and it will be defined in (22) below.

Let $G(c)$ denote the distribution function of networking cost $c$, where $G(0)=0$ and $G(\infty)=1 .^{12}$ An entrepreneur is willing to join the network if the cost of joining is not higher than its benefit. Thus, there is a threshold networking cost for each entrepreneur type, defined by $c_{i}^{*}=\mathcal{V}_{i}-\tilde{\mathcal{V}}_{i}$, with which the entrepreneur is indifferent between joining the network or not. Hence, the endogenous network size is given by

$$
\eta=\theta G\left(c_{H}^{*}\right)+(1-\theta) G\left(c_{L}^{*}\right)
$$

\footnotetext{
${ }^{12}$ One may propose considering a refund scheme to reimburse successful entrepreneurs of their entry cost. But, that would be ideal for formal networks rather than informal ones because in the latter the costs are more in terms of time and effort than a membership fee.
} 
If $G(\cdot)$ is a continuous distribution function, it is straightforward to show that there are more high-type entrepreneurs than low-type entrepreneurs in the network, i.e., $G\left(c_{H}^{*}\right)>G\left(c_{L}^{*}\right)$. If $G(\cdot)$ is discrete, the strict inequality is replaced by a weak inequality.

The payoff of a network entrepreneur depends on the information transmitted by the hub firm to the local financiers. Let $U_{i}^{z}$ denote the payoff of entrepreneur $i$, given that the hub firm implements some referral policy $z$ with respect to the information it reveals about network entrepreneurs to local financiers. The hub firm does not observe types directly, so it chooses its referral policy $z$ to maximize the total expected welfare of the network entrepreneurs, denoted by $\Omega$ :

$$
\Omega=\theta G\left(c_{H}^{*}\right) U_{H}^{z}+(1-\theta) G\left(c_{L}^{*}\right) U_{L}^{z} .
$$

There are three salient referral policies:

1. Truthful referral to local financiers of cases for which good signals are received, but concealment of cases for which no signal is received.

2. Truthful referral to local financiers of cases both for which good signals are received and for which no signal is received.

3. Biased referral to local financiers, whereby all members are claimed to have received a good signal even if they received no signal.

Policy 1 is the case discussed in the previous sections. In this case, $U_{i}^{1}=\mathcal{V}_{i}$ in (11) and (12), where now $\hat{p}$ and $\tilde{p}$ are given by

$$
\begin{aligned}
& \hat{p}=\frac{\theta G\left(c_{H}^{*}\right) x p_{H}+(1-\theta) G\left(c_{L}^{*}\right) y p_{L}}{\theta G\left(c_{H}^{*}\right) x+(1-\theta) G\left(c_{L}^{*}\right) y} \\
& \tilde{p}=\frac{\left[1-x G\left(c_{H}^{*}\right)\right] \theta p_{H}+\left[1-y G\left(c_{L}^{*}\right)\right](1-\theta) p_{L}}{\left[1-x G\left(c_{H}^{*}\right)\right] \theta+\left[1-y G\left(c_{L}^{*}\right)\right](1-\theta)} .
\end{aligned}
$$


Policy 2 allows local financiers to distinguish between three groups of borrowers: standalone entrepreneurs, network entrepreneurs with no signal, and network entrepreneurs with a good signal (see footnote 8 ). The average success probability of network entrepreneurs with a good signal continues to be given by $\hat{p}$ provided in (21). However, the success probabilities of stand-alone entrepreneurs and network entrepreneurs with no signal are given respectively by

$$
\begin{aligned}
& p_{s a}=\frac{\theta\left[1-G\left(c_{H}^{*}\right)\right] p_{H}+(1-\theta)\left[1-G\left(c_{L}^{*}\right)\right] p_{L}}{\theta\left[1-G\left(c_{H}^{*}\right)\right]+(1-\theta)\left[1-G\left(c_{L}^{*}\right)\right]} \\
& p_{n s}=\frac{G\left(c_{H}^{*}\right) \theta(1-x) p_{H}+G\left(c_{L}^{*}\right)(1-\theta)(1-y) p_{L}}{\left[G\left(c_{H}^{*}\right) \theta(1-x)+G\left(c_{L}^{*}\right)(1-\theta)(1-y)\right.},
\end{aligned}
$$

where $s a$ stands for stand alone and $n s$ for no signal. Payoffs under this referral policy are given by

$$
\begin{aligned}
U_{H}^{2} & =x p_{H}\left(Y-\frac{R I}{\hat{p}}\right)+(1-x) p_{H}\left(Y-\frac{R I}{p_{n s}}\right) \\
U_{L}^{2} & =y p_{L}\left(Y-\frac{R I}{\hat{p}}\right)+(1-y) p_{L}\left(Y-\frac{R I}{p_{n s}}\right) .
\end{aligned}
$$

Policy 3 has the hub firm telling local financiers that every member has a good signal. In that case, because the signal technology is common knowledge, local financiers will quickly see through this dissimulation, and consequently, they will price their loans in accordance with the actual average quality of the borrower pool in the network, not the declared quality claimed by the hub firm. Thus, the network has no role in project financing in this case.

We now answer which referral policy is best for the hub firm. Under policy 3, all network entrepreneurs are offered a loan contract with repayment $D=R / \bar{p}$. Hence, $U_{i}^{3}=\overline{\mathcal{V}}_{i}=$ $p_{i}(Y-D)$. But, this does not improve on the stand-alone option. Hence, nobody would pay to join the network, so $G\left(c_{i}^{*}\right)=0$ for each type and $\Omega=0$. Next, compare $\tilde{p}$ of (22) with $p_{n s}$. Given $G\left(c_{H}^{*}\right) \geq G\left(c_{L}^{*}\right)$ and $x>y$, it can be shown that $\tilde{p}>p_{n s}$. Hence, $0<U_{i}^{2}<U_{i}^{1}$ 
for each type. This means that policy 1 maximizes hub firm's objective function. We record this result in the next lemma.

Lemma 1 The optimal referral policy of the hub firm, whose objective is to maximize the welfare of the network entrepreneurs, is policy 1.

Lemma 1 shows that the referral policy discussed in Sections 3 and 4 of the paper is precisely the one which will be chosen by a utilitarian hub firm which cares only about the payoffs of its members. ${ }^{13}$ It can, therefore, be thought of as providing a rationale for our earlier treatment of old-boy networks. The intuition for Lemma 1 is straightforward: by identifying network members without a signal, policy 2 effectively labels such members as having a 'bad' signal. This controverts the hub's wish to promote the interests of all of its members, unlike policy 1 which gives members lacking signals better terms in the credit market. Indeed, this result and intuition clearly remain intact even if the hub firm has a different objective function which weights high types more than low types. The same imperative of caring about the outcomes of members lacking signals continues to apply irrespective of what type the members are and how favored types are by the hub relative to each other.

If there are multiple hub firms competing with each other, the dominance of policy 1 also appears to be robust to a less extreme version of policy 3, where a hub firm only modestly exaggerates the number of good signals. Once again, local financiers anticipate dissimulation by the hub firm, and hence price loans accordingly, which reflect the quality of the pool they actually observe.

To see this, suppose a competing hub firm exaggerates good signals, by claiming to local financiers that an additional fraction $\lambda>0$ (relative to policy 1) of its members have

\footnotetext{
${ }^{13}$ In general, it is not possible to extend the probability ordering to include $p_{s a}$. A special case where this is possible arises when $G\left(c_{H}^{*}\right) \approx G\left(c_{L}^{*}\right)$, for then $p_{s a}>\tilde{p}$. Note that $p_{s a}$ is not needed to prove Lemma 1 because the hub firm is not interested in the payoffs of stand-alone entrepreneurs.
} 
good signals. Given that signal technology is common knowledge, in equilibrium, the local financiers price to the average quality of this pool, anticipating that a fraction $\lambda$ of the pool actually received no signals. They anticipate that the actual average success probability of this group is

$$
p^{\lambda}=\frac{\theta G\left(c_{H}^{*}\right)[x+\lambda(1-x)] p_{H}+(1-\theta) G\left(c_{L}^{*}\right)[y+\lambda(1-y)] p_{L}}{\theta G\left(c_{H}^{*}\right)[x+\lambda(1-x)]+(1-\theta) G\left(c_{L}^{*}\right)[y+\lambda(1-y)]} .
$$

Now because $1-y>1-x, \hat{p}$ of (21) exceeds $p^{\lambda}$. Furthermore, the greater is $\lambda$, the larger the amount by which $\hat{p}$ exceeds $p^{\lambda}$. Therefore, payoffs of network entrepreneurs in the good state — which are disproportionately received by high-type entrepreneurs - are decreasing in $\lambda$. It follows that competing hub firms with lower $\lambda$ will attract high-type entrepreneurs away from hub firms with higher $\lambda$. Consequently, hub firms with higher $\lambda$ s will end up being dominated by low-type entrepreneurs, who end up obtaining a higher interest rate than $R / \bar{p}$. Hence, even low-type network entrepreneurs leave those networks. Eventually, only a hub firm offering $\lambda=0$ can retain high-type entrepreneurs and survive in equilibrium. The next lemma records this result.

Lemma 2 In an environment where multiple networks compete with each other, only the hub firms which do not exaggerate the number of good signals (i.e. Policies 1 and 2) exist in equilibrium.

Lemma 2 rules out the possibility of a referral policy which over-claims the number of good signals, in favor of policy 1 or policy 2 . But Lemma 1 has already shown that policy 1 dominates policy 2, confirming the former as the optimal referral policy.

The inefficiency associated with the network, stated in Proposition 3, now becomes clearer in the context of an endogenously formed network. Remember that in our setting all entrepreneurs have positive NPV projects. So, it is efficient to undertake all projects and thus they are going to be financed in any case. However, in the network regime, network entre- 
preneurs incur networking costs to get a purely redistributive gain in the form of better loan contract terms. This is inefficient from the point of view of the society. We record this result in the next proposition.

\section{Proposition 4 (Inefficiency) The network inefficiently forms.}

It is noteworthy that the hub firm honestly conveys its information about network entrepreneurs with a good signal. This means that there are no considerations of nepotism in this result other than the fact that not sharing the information about those who got no signals has some favoritism in it. So, even such a network may have negative welfare consequences.

Another important point to note is that, once one incorporates the assumption of heterogenous networking costs, the losers from network formation become a much bigger group, including some high-type entrepreneurs. To make our point, suppose for the moment that $G\left(c_{H}^{*}\right) \approx G\left(c_{L}^{*}\right)$ so that the fraction of high- and low-type entrepreneurs in and outside the network are the same, as in the exogenous network model. This allows us to make comparisons of some expressions derived in the exogenous network model with others derived in the endogenous network model. The marginal high type who is indifferent between joining the network and not joining is defined by $V_{H}-\tilde{V}_{H}=c_{H}^{*}$. Let us compare her payoff when there is a network, $V_{H}$, with her payoff when there is no network, $\bar{V}_{H}$. She would be better off with a network regime if $V_{H}-\bar{V}_{H}>c_{H}^{*}$. Incorporating the expression for $c_{H}^{*}$ yields $V_{H}-\bar{V}_{H}>V_{H}-\tilde{V}_{H}$, or $\tilde{V}_{H}>\bar{V}_{H}$. This requires $\tilde{p}>\hat{p}$, which never holds.

This means that the marginal high-type entrepreneur, who chooses to join the network at some point, would in fact be better off if there were no network now. One can repeat the same exercise for a low-type entrepreneur and obtain the same result. So, a positive mass of network members (composed of both high- and low-type entrepreneurs) whose networking costs are closer to the marginal networking cost joins the network even though each of them would be better off in a world with no networks. The next proposition records the result. 
Proposition 5 (Immiserizing Network Membership) A positive mass of high-and lowtype network entrepreneurs would be better off in a world without the network.

\section{Concluding remarks}

This paper analyzes the incentives for the existence of an old-boy network among heterogeneous entrepreneurs seeking external financing. It is not trivial to explain why a network owner forms an old-boy mechanism to decrease the information gap between network entrepreneurs and their financiers. We show that there can be market incentives to do so. The previous literature on entrepreneurial finance under asymmetric information has usu-

ally regarded efforts to separate hidden types (e.g., via screening or signaling) as conducive to greater efficiency. Our work contributes to that literature by exploring a novel inefficiency erected by the informal network's partial separation of hidden entrepreneurial types.

In the presence of asymmetric information between entrepreneurs and their financiers, the credit market undervalues the start-ups of high-type entrepreneurs and overvalues the start-ups of low-type entrepreneurs. When the network owner shares its information about the entrepreneurs in its network with the financiers, the levels of under- and overvaluation are altered for the network entrepreneurs. We show that this makes sometimes both types of entrepreneurs, and at other times only high-type entrepreneurs, better off. In the former case, as both groups of entrepreneurs are willing and able to provide side payments to the network owner, it is obvious that there are incentives to maintain the old-boy mechanism.

It also turns out that there are incentives to maintain the old-boy mechanism even in the latter case, when only high-type entrepreneurs benefit so that the interests of the two types of entrepreneurs conflict with each other. This is because the total side payments that high-type entrepreneurs are willing and able to offer to the network owner to induce it to maintain the old-boy mechanism are greater than the total side payments that low-type 
entrepreneurs are willing and able to pay to the network owner to induce it not to do so. This suggests that there are market incentives for the network owner to decrease the information gap between the entrepreneurs and their financiers. By endogenizing the network, we also show that the network forms even if it is inefficient because its benefit is purely redistributive while its cost, in the form of networking costs, is real.

Our work can be extended in several directions. If, for example, politicians are also members of informal networks, they might be able to 'grease the wheels' of business and enable co-member entrepreneurs to enjoy benefits from network membership which compensate them for having to comply with costly regulations (Meon and Sekkat, 2005). This could generate effects that are not discussed in this paper. Whether the non-members would still lose less in aggregate than the members gained might now depend on the nature of the regulations. A second extension of the model, also in a second-best setting, might combine hidden actions with hidden types. Non-members might have to expend more privately costly effort than members to compensate for their group status. If members then responded by increasing their effort as well to preserve the separation of types afforded by the network, then the overall effect on efficiency might be positive.

Despite the fact that networks and social connections play a great role in many economic circumstances, there is surprisingly little work in economics on their welfare consequences. The overwhelming consensus in the existing literature is that social networks have positive effects in the society, as a conduit for leveraging social capital. For, example, Montgomery (1991) argues that social networks enhance efficiency by allowing employers to infer hidden abilities of workers with greater certainty. Bruderl and Preisendorfer (1998) and Aldrich and Zimmer (1986) discuss positive effects of networks in entrepreneurship. In this paper, we identify a novel channel resulting in negative effects of informal networks even when they are not nepotistic. The practical implications of this new channel should be embedded into policy discussions. We hope that future research will further enhance our understanding of the efficiency and welfare implications of informal networks. 


\section{A Appendix: proofs}

\section{A.1 Proof of Proposition 1}

If the difference between $\mathcal{V}_{H}$ and $\overline{\mathcal{V}}_{H}$ is positive, the market value of the start-up of a hightype network entrepreneur increases due to the old-boy mechanism. That is, $\mathcal{V}_{H}-\overline{\mathcal{V}}_{H}>0$ should hold. Manipulating this yields

$$
\frac{x}{\hat{p}}+\frac{(1-x)}{\tilde{p}}<\frac{1}{\bar{p}}
$$

By substituting for $\tilde{p}, \bar{p}$, and $\hat{p}$, we get

$$
\frac{\left(p_{H}-p_{L}\right)(x-y)(1-\theta) \theta\left[x p_{H}(1-\eta) \theta+(x-\eta y) p_{L}(1-\theta)\right]}{[\theta x+(1-\theta) y][1-\eta(\theta x+y(1-\theta))]}>0
$$

It can be easily verified that the terms $\left(p_{H}-p_{L}\right)(x-y)(1-\theta) \theta$ and $[\theta x+(1-\theta) y]$ are positive. The term $1-\eta(\theta x+y(1-\theta))$ is also positive because $\theta x+(1-\theta) y$ is a weighted average of $x$ and $y$, and therefore it is between $x$ and $y$. Multiplying this by $\eta$, one gets a number between $\eta x$ and $\eta y$, which is definitely less than 1 . This means that (A-2) always holds and therefore the old-boy mechanism always benefits a high-type network entrepreneur.

Now, consider a low-type network entrepreneur. The market value of her start-up increases due to the old-boy mechanism if the difference between $\mathcal{V}_{L}$ and $\overline{\mathcal{V}}_{L}$ is positive. That is, $\mathcal{V}_{L}-\overline{\mathcal{V}}_{L}>0$ should hold. Manipulating this yields

$$
\frac{y}{\hat{p}}+\frac{(1-y)}{\tilde{p}}<\frac{1}{\bar{p}}
$$

By substituting for $\tilde{p}, \bar{p}$, and $\hat{p}$, we get

$$
\frac{\left(p_{H}-p_{L}\right)(x-y)(1-\theta) \theta\left[(x \eta-y) p_{H} \theta-p_{L} y(1-\eta)(1-\theta)\right]}{[\theta x+(1-\theta) y][1-\eta(\theta x+y(1-\theta))]}<0
$$


It can be easily verified that the terms $\left(p_{H}-p_{L}\right)(x-y)(1-\theta) \theta$ and $[\theta x+(1-\theta) y]$ are positive. Above, we have already shown that $1-\eta(\theta x+y(1-\theta))>0$. It is left to determine when

$$
(x \eta-y) p_{H} \theta-p_{L} y(1-\eta)(1-\theta)<0
$$

holds, which yields eqs. (13)-(15). Therefore, the old-boy mechanism benefits low-type network entrepreneurs if $x / y<\left[\theta p_{H}+(1-\theta)(1-\eta) p_{L}\right] /\left(\eta \theta p_{H}\right)$ (given the network size and the fraction of high-type entrepreneurs), $\eta<\left[y\left(\theta p_{H}+(1-\theta) p_{L}\right)\right] /\left[\theta x p_{H}+(1-\theta) y p_{L}\right]$ (given the signal structure and the fraction of high-type entrepreneurs), and $\theta<\left[p_{L} y(1-\eta)\right] /[(x \eta-$ y) $\left.p_{H}+p_{L} y(1-\eta)\right]$ (given the network size and the signal structure).

Note that all $\theta \in(0,1)$ satisfy $(15)$ if the network is sufficiently small $(i . e ., \eta<y / x)$ and $(x \eta-y) p_{H}+p_{L} y(1-\eta)>0$ because in such a case the right-hand side of the inequality is always greater than 1 (We exclude $\theta=0$ and $\theta=1$ because there would be no asymmetric information in these cases). If $(x \eta-y) p_{H}+p_{L} y(1-\eta)<0$, then there is no $\theta$ satisfying (15) because $\theta$ cannot be negative.

\section{A.2 Proof of Proposition 2}

Since there is a conflict of interest in this case, we have $\mathcal{V}_{H}-\overline{\mathcal{V}}_{H}>0$ for a high-type network entrepreneur (and there are $\theta$ of them) but $\overline{\mathcal{V}}_{L}-\mathcal{V}_{L}>0$ for a low-type network entrepreneur (and there are $1-\theta$ of them). Hence, the total increase in the value of the start-ups of hightype entrepreneurs due to the old-boy mechanism is higher than the total decrease in the value of the start-ups of low-type entrepreneurs as long as $\theta\left(\mathcal{V}_{H}-\overline{\mathcal{V}}_{H}\right)>(1-\theta)\left(\overline{\mathcal{V}}_{L}-\mathcal{V}_{L}\right)$ holds. Expanding this inequality yields

$$
\theta\left(-x p_{H} \frac{R I}{\hat{p}}-(1-x) p_{H} \frac{R I}{\tilde{p}}+p_{H} \frac{R I}{\bar{p}}\right)>(1-\theta)\left(-p_{L} \frac{R I}{\bar{p}}+y p_{L} \frac{R I}{\hat{p}}+(1-y) p_{L} \frac{R I}{\tilde{p}}\right)
$$


After substituting for $\bar{p}, \tilde{p}$, and $\hat{p}$ and simplifying the expression, we get

$$
-\frac{\left(p_{H}-p_{L}\right)(x-y)(1-\eta)(1-\theta) \theta}{p_{L}(1-y \eta)(1-\theta)+p_{H}(1-x \eta) \theta}<0 .
$$

It is obvious that this inequality always holds.

\section{B Appendix: extensions}

\section{B.1 Fraction of high-type entrepreneurs in and outside the net- work}

We assume in the exogenous network model that ex ante the fraction of high-type network entrepreneurs is equal to the fraction of high-type stand-alone entrepreneurs. However, the endogenous network model showed that there is always a higher fraction of high-type entrepreneurs in the network than outside it. To show that our results in the exogenous network model are independent of this assumption, suppose now $\theta$ fraction of the network entrepreneurs and $\gamma<\theta$ fraction of the stand-alone entrepreneurs are high-type entrepreneurs. Now, there is an additional benefit of being in the network for low-type entrepreneurs and this would strengthen all our results. As stated by Bruderl and Preisendorfer (1998), this assumption is in fact one of the robust empirical observation of the "network approach to entrepreneurship" initiated by Aldrich and Zimmer (1986). One can now show that (A-5) becomes

$$
x \eta p_{H} \theta-[\eta \theta+(1-\eta) \gamma] y p_{H}-p_{L} y(1-\eta)(1-\gamma)<0 .
$$

This suggests that, all else equal, low-type entrepreneurs prefer the old-boy mechanism when $\theta$ is sufficiently low and $\gamma$ is sufficiently high. The intuition is similar to what we provide in the text. When $\theta$ is sufficiently low, it will be relatively close to $\gamma$, which means 
that if a low-type entrepreneur does not get a good signal, she will be relatively less worse off, and if she gets a good signal her project will be even more overvalued compared with the case in which $\theta$ is higher. Similarly, when $\gamma$ is higher, the downside is relatively less important for a low-type entrepreneur because $\gamma$ will be relatively closer to $\theta$ and thus the outcome in the case in which she is left out of the network is relatively closer to the case in which there is no network.

\section{B.2 Reliability of signals}

An implicit assumption on which the results are predicated is that the hub firm honestly conveys the information it has to the local financiers. In reality, the credibility of the signals is questionable. One way for local financiers to overcome this problem is to finance the start-ups in which the hub firm is also a claimant. That is, if the hub firm claims that the entrepreneurs it mentions have higher average success probabilities, then it should also be willing to invest in their projects. Put another way, the signals should be credible if the hub firm holds a sufficient amount of equity in the portfolio of start-ups it labels with good signals. This appendix shows this result formally.

Suppose the hub firm has $\eta(\theta x+(1-\theta) y) W$ units of capital that it can allocate for investment in the start-ups of the network entrepreneurs. We assume that this wealth is observable by local financiers and that $W<I$. We also assume that the local financiers can verify whether the hub firm in fact invested in the start-ups of the network entrepreneurs. There are $\eta(\theta x+(1-\theta) y)$ network entrepreneurs that the hub firm labels with a good signal. An optimal investment strategy for the hub firm is to invest an equal share of its wealth endowment into these start-ups, which means that it invests $W$ units of capital in each start-up in its portfolio to get an $\alpha<1$ share of each of them. 
If the hub firm extracts the information, its payoff is

$$
\eta(\theta x+(1-\theta) y)[\alpha \hat{p}(Y-R(I-W))-R W]-\eta C .
$$

The first term is the net return on investment. It gets an $\alpha$ share of each start-up by paying $W$ for each. There are $\eta(\theta x+(1-\theta) y)$ such entrepreneurs and their average success probability is $\hat{p}$. These entrepreneurs need only $I-W$ units of capital from local financiers to start their firms. The second term is the cost to the hub firm of extracting information: $C>0$.

Alternatively, the hub firm can choose $\eta[\theta x+(1-\theta) y]$ entrepreneurs randomly without incurring the cost of information extraction and announce them as the ones with good signals to the local financiers. If it does that, the average success probability in this random sample is going to be $\bar{p}<\hat{p}$. This time, the payoff to the hub firm is

$$
\eta(\theta x+(1-\theta) y)[\alpha \bar{p}(Y-R(I-W))-R W] .
$$

A simple comparison of (B-2) and (B-3) shows that, given $W$, reporting signals honestly is preferable by the hub firm if it buys a sufficiently large share of each start-up:

$$
\alpha>\frac{C}{(\theta x+(1-\theta) y)(Y-R(I-W))(\hat{p}-\bar{p})} .
$$

This suggests not only that the signals of the hub firm are reliable if it invests in the portfolio of the start-ups for which it sends good signals to the local financiers but also that a hub firm has to have deep pockets to organize a credible old-boy mechanism. Lamoreaux et al. (2007) provide evidence for both of these conditions. The result of this appendix is summarized in the following proposition:

Proposition 6 (Reliability of Signals) The signals of the hub firm are reliable if it buys 
a sufficiently large share of the portfolio of start-ups for which it sends good signals to local financiers.

\section{References}

[1] Aldrich, H. and C. Zimmer, 1986, "Entrepreneurship through Social Networks," D. Sexton and R. Smilor, eds., The Art and Science of Entrepreneurship, Ballinger.

[2] Amatucci, F. M. and J. E. Sohl, 2007, "Business Angels: Investment Processes, Outcomes and Current Trends," A. Zacharakis and S. Spinelli Jr., eds., Entrepreneurship: The Engine of Growth Volume 2, Praeger.

[3] Bac, M. and E. Inci, 2010, "The Old-boy Network and the Quality of Entrepreneurs," Journal of Economics $\&$ Management Strategy, 19, 889-918.

[4] Bergemann, D., and U. Hege, 1998, "Venture Capital Financing, Moral Hazard, and Learning," Journal of Banking and Finance, 22, 703-735.

[5] Bester, H., 1985, "Screening vs. Rationing in Credit Markets with Imperfect Information," American Economic Review, 75, 850-855.

[6] Bruderl, J. and P. Preisendorfer, 1998, "Network Support and the Success of Newly Founded Businesses," Small Business Economics, 10, 213-225.

[7] Campbell, T. and W. Kracaw, 1980, "Information Production, Market Signaling, and the Theory of Financial Intermediation," Journal of Finance, 35, 863-882.

[8] Cornelli, F., and O. Yosha, 2003, "Staged Financing and the Role of Convertible Securities," Review of Economic Studies, 70, 1-32.

[9] Chamley, C., 1983, "Entrepreneurial Abilities and Liabilities in a Model of SelfSelection," Bell Journal of Economics, 14, 70-80. 
[10] de Meza, D. and D. Webb, 1987, "Too Much Investment: A Problem of Asymmetric Information," Quarterly Journal of Economics, 102, 281-292.

[11] Diamond, D., 1993, "Seniority and Maturity of Debt Contracts," Journal of Financial Economics, 33, 341-368.

[12] Inci, E., 2006, "Occupational Choice and the Quality of Entrepreneurs," Boston College Working Paper, 666.

[13] Ioannides, Y. and L. Loury, 2004, "Job Information Networks, Neighborhood Effects, and Inequality," Journal of Economic Literature, 42, 1056-1093.

[14] Kaplan, S. and P. Stromberg, 2001, "Venture Capitalists as Principals: Contracting, Screening and Monitoring," American Economic Review Papers $\&$ Proceedings, 91(2), 426-430.

[15] Lamoreaux, N., M. Levenstein and K. Sokoloff, 2007, "Financing Invention During the Second Industrial Revolution: Cleveland, Ohio, 1870-1920," N. Lamoreaux, K. Sokoloff, eds., Financing Innovation in the United States, 1870 to Present, Cambridge, MA: The MIT Press.

[16] Meon, P. and K. Sekkat, 2005, "Does Corruption Grease or Sand the Wheels of Growth?," Public Choice, 122, 69-97.

[17] Montgomery, J., 1991, "Social Networks and Labor-market Outcomes: Toward an Economic Analysis," American Economic Review, 81, 1408-1418.

[18] Nofsinger, J. R. and W. Wang, 2011, "Determinants of Start-Up Firm External Financing Worldwide, " Journal of Banking and Finance, 35, 2282-2294.

[19] Nanda, R. and T. Khanna, 2010, "Diasporas and Domestic Entrepreneurs: Evidence from the Indian Software Industry," Journal of Economics 83 Management Strategy, 19, 991-1012. 
[20] Orzach, R. and Y. Tauman, 2005, "Strategic Dropouts," Games and Economic Behavior, 50, 79-88.

[21] Parker, S. C., 2008, "The Economics of Formal Business Networks," Journal of Business Venturing, 23, 627-640.

[22] Ray, D., 1998, Development Economics, Princeton: Princeton University Press.

[23] Saloner, G., 1985, "Old Boy Networks as Screening Mechanisms," Journal of Labor Economics, 3, 255-267.

[24] Scott, J., 1991, Social Network Analysis, Newbury Park: Sage.

[25] Shane, S. and D. Cable, 2002, "Network Ties, Reputation and the Financing of New Ventures," Management Science, 48, 364-81.

[26] Taylor, C., 2000, "The Old-boy Network and the Young-gun Effect," International Economic Review, 41, 871-891. 